\title{
BRPKM
}

Buletin Riset Psikologi dan Kesehatan Mental

http://e-journal.unair.ac.id/index.php/BRPKM

e-ISSN: 2776-1851

\section{Sikap terhadap Gangguan Mental pada Mahasiswa Psikologi Universitas Airlangga Berdasarkan Jenis Kelamin}

\author{
GRACE RIRIN \& ATIKA DIAN ARIANA* \\ Fakultas Psikologi Universitas Airlangga
}

\begin{abstract}
ABSTRAK
Keyakinan seperti stereotip dan prasangka maupun sikap yang menunjukkan diskriminasi tetap dapat ditemukan pada mereka yang memiliki gangguan mental meskipun gangguan mental dapat dialami oleh siapa saja. Sikap terhadap gangguan mental adalah penilaian evaluatif yang dibentuk dari pengetahuan dan interaksi dengan penderita gangguan mental. Penelitian ini bertujuan untuk melihat perbedaan sikap terhadap gangguan mental pada mahasiswa psikologi Universitas Airlangga berdasarkan jenis kelamin. Penelitian kuantitatif ini menggunakan metode pengambilan data survei yang dilakukan pada 210 sampel mahasiswa psikologi Universitas Airlangga, terdiri dari 169 mahasiswa perempuan dan 41 mahasiswa laki-laki. Skala yang digunakan untuk mengukur sikap terhadap gangguan mental adalah Mental Illness: Clinicians' Attitude versi 4 (MICA-4). Penelitian ini menggunakan uji t independen sebagai metode analisis data. Hasil analisis data menunjukkan terdapat perbedaan sikap yang signifikan terhadap gangguan mental berdasarkan jenis kelamin partisipan $(\mathrm{t}=-2,815 ; p<0,05)$. Perempuan $(M=2,81 ; S D=0,401)$ menunjukkan sikap lebih positif terhadap gangguan mental dibanding laki-laki $(\mathrm{M}=3,01 ; \mathrm{SD}=0,395)$.
\end{abstract}

Kata kunci: sikap terhadap gangguan mental

\begin{abstract}
Beliefs such as stereotypes and prejudice along with attitude which indicate discrimination can still be found in those with mental disorders, despite the fact that mental disorders could happen to anyone. Attitude towards mental disorders is an evaluative judgement shaped by knowledge and interaction with people who suffered from mental disorders. This study aimed to see the difference in attitude of Universitas Airlangga psychology students towards mental disorders based on their gender. This quantitative research used survey as data collection method with sample of 210 students from Universitas Airlangga, consist of 169 females and 41 males. Attitude towards mental disorders is measured by Mental Illness: Clinicians' Attitude Scale 4th version (MICA-4), analyzed using independent sample t-test. Difference in attitude towards mental disorders based on gender was found significant $(\mathrm{t}=-2,815 ; \mathrm{p}<0,05)$. Females $(\mathrm{M}=2,81 ; \mathrm{SD}=0,401)$ were found to have more positive attitude towards mental disorders than males $(\mathrm{M}=3,01 ; \mathrm{SD}=0,395)$.
\end{abstract}

Keywords: attitude towards mental disorders

Buletin Penelitian Psikologi dan Kesehatan Mental (BRPKM), 2021, Vol. 1(1), 1030-1036

*Alamat korespondensi: Fakultas Psikologi Universitas Airlangga, Kampus B Universitas Airlangga Jalan

Airlangga 4-6 Surabaya 60286. Surel: atika.ariana@psikologi.unair.ac.id 
Naskah ini merupakan naskah dengan akses terbuka dibawah ketentuan the Creative Common Attribution License (CC-BY-4.0) (http://creativecommons.org/licenses/by/4.0), sehingga penggunaan, distribusi, reproduksi dalam media apapun atas artikel ini tidak dibatasi, selama sumber aslinya disitir dengan baik.

\section{PENDAHULUAN}

Riset Kesehatan Dasar (Kemenkes RI, 2019) menyebutkan bahwa prevalensi penduduk dengan gangguan jiwa skizofrenia/psikosis di Indonesia sebesar 6,7\% dan prevalensi depresi pada penduduk dengan usia lebih dari 15 tahun sebesar 6,1\%. Prevalensi gangguan mental emosional pada penduduk dengan usia lebih dari 15 tahun adalah sebesar 9,8\%, yang artinya hampir 18 juta penduduk Indonesia menderita gangguan mental emosional. Angka prevalensi di atas menunjukkan bahwa gangguan mental dapat dialami oleh siapa saja. Meskipun banyak orang yang memiliki gangguan mental, keyakinan seperti stereotip dan prasangka maupun sikap yang menunjukkan diskriminasi tetap saja dapat ditemukan pada mereka yang memiliki gangguan mental. Hal tersebut menyebabkan orang-orang yang mendapatkan label gangguan mental kehilangan banyak kesempatan untuk mencapai tujuan hidup (Corrigan, 2004).

Sikap seseorang terhadap gangguan mental terbentuk dari pemahaman pribadi mengenai gangguan mental, interaksi dengan seseorang yang memiliki gangguan mental, dan stereotip mengenai gangguan mental. Sikap dan pemikiran yang ditunjukkan secara positif dapat menghasilkan perilaku yang supportive, sedangkan sikap yang ditunjukkan secara negatif dapat mengakibatkan timbulnya penolakan hingga diskriminasi pada penderita gangguan mental (Centers for Disease Control and Prevention, 2012).

Sikap terhadap gangguan mental terbentuk dari stigma. Stigma adalah sebuah proses sosial yang ditandai dengan pengecualian, penolakan, atau kesalahan yang merupakan akibat dari social judgment yang merugikan seseorang atau kelompok tertentu. Penilaian ini diambil berdasarkan identitas yang disebabkan oleh masalah kesehatan atau kondisi terkait kesehatan dan biasanya tidak memiliki alasan medis yang jelas (Weiss dkk., 2006). Ketika stigma mendorong seseorang untuk melakukan diskriminasi terhadap orang dengan gangguan mental, kesempatan untuk mendapatkan pendidikan, pekerjaan, dan pelayanan kesehatan yang berkualitas menjadi terhalang. Stigma juga dapat menggagalkan kesempatan seseorang untuk mencapai tujuan hidupnya (Corrigan dkk., 2004).

Pembentukan sikap terhadap gangguan mental juga dapat dipengaruhi oleh keyakinan pribadi, pengetahuan akan gangguan mental, status sosial ekonomi, profesi karir, usia, status pernikahan, dan jenis kelamin (Reimer, 2019). Penelitian dengan topik sikap terhadap gangguan mental khususnya ketika melihat perbedaan berdasarkan jenis kelamin sering mendapatkan variasi hasil penelitian yang berbeda (Jang dkk., 2012; Holzinger dkk., 2012).

Beberapa penelitian menunjukkan hasil yang berbeda mengenai sikap terhadap gangguan mental berdasarkan jenis kelamin partisipannya. Studi yang dilakukan oleh Pascucci dan kawan-kawan (2017) pada mahasiswa kedokteran di Italia menyatakan bahwa partisipan perempuan lebih menunjukkan sikap positif terhadap penderita gangguan mental daripada laki-laki. Hasil serupa juga ditunjukkan oleh Puspitasari dan kawan-kawan (2020) terhadap mahasiswa di Indonesia dan studi yang dilakukan oleh Smith dan kawan-kawan (2011) di mana perempuan lebih menunjukkan sikap yang positif terhadap skizofrenia daripada laki-laki. Namun hasil berbeda ditunjukkan Bener dan Ghuloum (2011) dan Abolfotouh dan kawan-kawan (2019) di mana laki-laki lebih menunjukkan sikap yang lebih positif terhadap gangguan mental daripada perempuan. Penemuan lainnya ditemukan oleh Salve dan kawan-

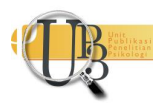


kawan (2013) yang menyatakan tidak ditemukan adanya perbedaan sikap yang signifikan antara lakilaki maupun perempuan.

Literatur penelitian seputar sikap psikolog terhadap gangguan mental mendapatkan hasil penelitian yang bervariasi dan juga bertolak belakang. Ada banyak penelitian dengan topik gangguan mental, namun masih sedikit penelitian mengenai sikap terhadap gangguan mental khususnya pada mahasiswa psikologi. Mahasiswa psikologi dipilih sebagai subjek dalam penelitian ini karena psikologi merupakan ilmu yang tidak murni kesehatan, sehingga ada kemungkinan kepedulian terhadap gangguan mental perlu diasah lebih dalam dibandingkan dengan mahasiswa yang mempelajari ilmu kesehatan.

Idealnya adalah seluruh mahasiswa psikologi baik perempuan maupun laki-laki memiliki sikap positif terhadap gangguan mental. Sebagai calon profesional di bidang kesehatan mental, sikap negatif terhadap gangguan mental yang diabaikan di masa pendidikan dapat merugikan penderita gangguan mental yang mungkin akan dijumpai di masa yang akan datang, sehingga dapat dikatakan penting untuk mengetahui sikap mahasiswa psikologi terhadap gangguan mental. Variasi hasil penelitian berdasarkan jenis kelamin yang berbeda juga mendorong pentingnya dilakukan penelitian ini. Berdasarkan latar belakang yang telah diuraikan, maka tujuan dari penelitian ini adalah untuk mengetahui apakah terdapat perbedaan sikap terhadap gangguan mental pada mahasiswa Fakultas Psikologi Universitas Airlangga berdasarkan jenis kelamin.

\section{Desain Penelitian}

\section{METODE}

Penelitian ini menggunakan pendekatan kuantitatif dengan metode survei. Sikap terhadap gangguan mental diukur menggunakan skala Mental Illness: Clinicians' Attitude versi 4 (MICA-4). Uji validitas dilakukan dengan membandingkan nilai $r$ hitung (corrected item-total correlation) dengan nilai $\mathrm{r}$ tabel, sedangkan uji reliabilitas menggunakan koefisien cronbach alpha. Tujuan dari penelitian ini adalah untuk melihat perbedaan sikap pada gangguan mental pada mahasiswa psikologi berdasarkan jenis kelaminnya, sehingga teknik analisis data yang digunakan adalah independent sample t-test pada aplikasi IBM SPSS 26 for Mac.

\section{Partisipan}

Partisipan dalam penelitian ini dipilih menggunakan teknik nonprobability sampling dengan kriteria terdaftar sebagai mahasiswa Fakultas Psikologi Universitas Airlangga dan memiliki jenis kelamin lakilaki atau perempuan. Penelitian ini melibatkan 210 partisipan $\left(M_{\text {usia }}=20,14 ; S D_{\text {usia }}=0,95\right)$ dengan dominasi perempuan berjumlah 169 orang (80,5\%), sedangkan laki-laki berjumlah 41 orang (19,5\%).

\section{Pengukuran}

Penelitian ini mengukur perbedaan sikap terhadap gangguan mental berdasarkan jenis kelamin partisipan. Partisipan dengan jenis kelamin perempuan akan diberi kode 1, sedangkan partisipan dengan jenis kelamin laki-laki akan diberi kode 2. Sikap terhadap gangguan mental diukur dengan skala Mental Illness: Clinician's Attitude versi 4 (MICA-4). Terdapat 16 pernyataan dengan 6 pilihan jawaban dan mencakup pertanyaan favorable dan unfavorable. Skor skala MICA-4 seseorang adalah jumlah total dari skor untuk item individu. Skor untuk setiap item dijumlahkan untuk menghasilkan skor secara keseluruhan. Total skor yang tinggi menunjukkan sikap yang lebih negatif (stigma). Hasil analisis reliabilitas skala MICA-4 masuk dalam kategori reliabel (16 aitem; $\alpha=.606$ ). 


\section{Analisis Data}

Teknik analisis data yang digunakan adalah independent sample t-test untuk melihat perbedaan sikap terhadap gangguan mental berdasarkan jenis kelamin. Seluruh analisis statistik menggunakan bantuan aplikasi IBM SPSS 26 for Mac.

\section{HASIL PENELITIAN}

Hasil analisis deskriptif menunjukkan rata-rata partisipan dalam penelitian ini cenderung menunjukkan sikap positif terhadap gangguan mental $(N=210 ; M=2,85 ; S D=.406)$. Penulis melakukan analisis independent sample t-test untuk menguji ada tidaknya perbedaan sikap terhadap gangguan mental pada mahasiswa psikologi Universitas Airlangga. Hasil analisis menunjukkan terdapat perbedaan sikap yang signifikan terhadap gangguan mental antara laki-laki dan perempuan $(t(208)=-2,815 ; p=0,008)$. Perempuan $(M=2,81 ; S D=0,401)$ menunjukkan sikap yang lebih positif terhadap gangguan mental dibanding laki-laki $(M=3,01 ; S D=0,395)$.

\section{DISKUSI}

Sikap terhadap gangguan mental adalah penilaian evaluatif yang dibentuk melalui pengetahuan dan hasil interaksi dengan orang dengan gangguan mental. Pengetahuan yang baik akan gangguan mental akan membantu seseorang menunjukkan sikap positif melalui perilaku mendukung (Centers for Disease Control and Prevention, 2012). Sebaliknya, sikap negatif yang dipengaruhi oleh kesalahpahaman mengenai gangguan mental akan memunculkan perilaku diskriminasi khususnya pada penderita gangguan mental (Corrigan \& Watson, 2002). Kesalahpahaman mengenai gangguan mental merupakan stigma yang menjadi salah satu faktor yang mempengaruhi sikap. Stigma terdiri dari tiga struktur sosialkognitif yaitu stereotip, prasangka, dan diskriminasi (Gaebel dkk., 2016). Selain diskriminasi, stigma mengakibatkan penderita gangguan mental kehilangan kesempatan untuk menjalani hidup yang berkualitas seperti mendapat pekerjaan, tinggal di tempat yang aman, dan menerima perawatan kesehatan yang memuaskan (Corrigan \& Watson, 2002).

Salah satu faktor yang membentuk sikap terhadap gangguan mental adalah profesi karir (Reimer, 2019). Mereka yang berada di lingkup kesehatan seperti tenaga perawatan kesehatan dan mahasiswa kedokteran, keperawatan, dan psikologi memiliki peran yang cukup penting dalam penanganan gangguan jiwa sehingga sikap mereka sangat mempengaruhi kondisi para penderita gangguan jiwa (Natalia dkk., 2019). Sikap positif dan tepat dapat mendorong perawatan, edukasi kesehatan, dan rehabilitasi antara tenaga kesehatan dan penderita gangguan mental berjalan dengan aktif (Salve dkk., 2013).

Penelitian ini menggunakan skala MICA-4 di mana dari rentang angka rata-rata satu sampai enam, semakin mendekati angka enam maka semakin negatif sikap yang ditunjukkan. Hasil penelitian menunjukkan rata-rata partisipan dalam penelitian ini yaitu mahasiswa psikologi Universitas Airlangga cenderung menunjukkan sikap positif terhadap gangguan mental $(M=2,85)$. Hasil serupa dengan subjek di bidang yang sama yaitu mahasiswa psikologi juga dapat ditemukan di penelitian yang dilakukan Boyle (2014). Pentingnya sikap positif yang ditunjukkan tenaga kesehatan pada penderita gangguan mendorong banyak penelitian dengan topik serupa. Profesional kesehatan mental memiliki sikap yang jauh lebih positif terhadap gangguan mental (Natalia dkk., 2019; Yuan dkk., 2017).

Penelitian ini bertujuan untuk mengetahui perbedaan sikap terhadap gangguan mental pada mahasiswa psikologi berdasarkan jenis kelamin dengan variabel bebas jenis kelamin dan variabel terikat sikap

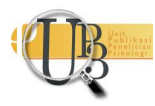


terhadap gangguan mental. Analisis data menggunakan teknik independent sample t-test dengan hasil analisis terdapat perbedaan sikap yang signifikan terhadap gangguan mental pada mahasiswa psikologi Universitas Airlangga berdasarkan jenis kelamin $(\mathrm{t}(208)=-2,815 ; \mathrm{p}<0,05)$. Perempuan $(\mathrm{M}=2,81$; $\mathrm{SD}=0,4017$ ) menunjukkan sikap yang lebih positif terhadap gangguan mental dibanding laki-laki $(M=3,01 ; S D=0,395)$. Hasil penelitian ini didukung oleh beberapa penelitian yang menunjukkan adanya perbedaan yang signifikan antara laki-laki dan perempuan terhadap gangguan mental (Ewalds-Kvist dkk., 2013; Pascucci dkk., 2017; Puspitasari dkk., 2020). Partisipan perempuan lebih menunjukkan sikap positif terhadap penderita gangguan mental daripada laki-laki (Pascucci dkk., 2017; Ewalds-Kvist dkk., 2013).

Perempuan memiliki toleransi yang lebih baik daripada laki-laki, sehingga dapat menjadi faktor pendukung dalam membentuk sikap positif terhadap gangguan mental (Holzinger dkk., 2012). Meskipun terdapat ketakutan dan keinginan untuk menghindar, besarnya empati yang dimiliki oleh perempuan menjadi salah satu faktor pendorong bagaimana sikap positif lebih ditunjukkan perempuan daripada laki-laki (Holzinger dkk., 2012; Ewalds-Kvist dkk., 2013).

Hasil penelitian ini menunjukkan adanya perbedaan sikap terhadap gangguan mental berdasarkan jenis kelamin partisipannya, namun ada juga hasil penelitian lain yang menunjukkan tidak ditemukan perbedaan sikap yang signifikan terhadap gangguan mental berdasarkan jenis kelamin (Boyle, 2014; Salve dkk., 2013; Reimer, 2019). Meskipun terdapat beberapa penelitian dengan hasil yang serupa, terdapat juga hasil penelitian yang berbeda. Hal ini dapat terjadi karena pengaruh faktor yang tidak diteliti dalam penelitian ini.

Penelitian ini memiliki keterbatasan yang bisa dijadikan bahan penelitian selanjutnya antara lain faktor yang dapat membangun sikap positif terhadap gangguan mental. Selain itu, masih sedikit penelitian sikap terhadap gangguan mental dengan subjek penelitian mahasiswa di bidang kesehatan. Penelitian dengan topik serupa yang dilakukan pada jumlah subjek yang lebih besar dan luas contohnya seperti mahasiswa psikologi di Indonesia sangat disarankan untuk memperkaya hasil penelitian yang telah dilakukan sebelumnya.

Sikap positif sangat dibutuhkan penderita gangguan mental untuk mengoptimalkan kondisinya, khususnya positif yang ditunjukkan orang-orang di sekeliling mereka. Profesional kesehatan dan mahasiswa di bidang kesehatan memiliki peran penting karena dekat dengan para penderita gangguan mental, khususnya mahasiswa psikologi. Ketika ditemukan sikap negatif terhadap gangguan mental dan diabaikan di masa pendidikan, hal ini dapat merugikan penderita gangguan mental yang mungkin dijumpai saat menjadi profesional di masa yang akan datang.

\section{SIMPULAN}

Penelitian ini dilakukan untuk mengetahui ada atau tidak adanya perbedaan sikap terhadap gangguan mental pada mahasiswa psikologi Universitas Airlangga berdasarkan jenis kelaminnya, di mana hasil penelitian menunjukkan terdapat perbedaan perbedaan sikap terhadap gangguan mental berdasarkan jenis kelamin. Hasil penelitian ini juga menunjukkan bahwa mahasiswa psikologi Universitas Airlangga cenderung menunjukkan sikap yang positif terhadap gangguan mental. Sikap terhadap gangguan mental dibentuk melalui pengetahuan, hasil interaksi, dan stereotip terhadap gangguan mental. Beberapa faktor lain yang dapat mempengaruhi sikap terhadap gangguan mental yaitu keyakinan dan nilai agama, status sosial ekonomi, usia, status pernikahan, dan jenis kelamin. 


\section{UCAPAN TERIMAKASIH}

Penulis mengucapkan terima kasih kepada Atika Dian Ariana S.Psi., M.Sc. selaku dosen pembimbing dan seluruh pihak yang terlibat dalam proses menyelesaikan penelitian ini.

\section{DEKLARASI POTENSI TERJADINYA KONFLIK KEPENTINGAN}

Grace Ririn dan Atika Dian Ariana tidak bekerja, menjadi konsultan, memiliki saham, atau menerima dana dari perusahaan atau organisasi manapun yang mungkin akan mengambil untung dari diterbitkannya naskah ini.

\section{PUSTAKA ACUAN}

Abolfotouh, M. A., Almutairi, A. F., Almutairi, Z., Salam, M., Alhashem, A., Adlan, A. A., \& Modayfer, 0. (2019). Attitudes toward mental illness, mentally ill persons, and help-seeking among the Saudi public and sociodemographic correlates. Psychology Research and Behavior Management, 12, 4554. https://doi.org/10.2147/PRBM.S191676

Bener, A., \& Ghuloum, S. (2011). Gender differences in the knowledge, attitude and practice towards mental health illness in a rapidly developing Arab society. International Journal of Social Psychiatry, 57(5), 480-486. https://doi.org/10.1177/0020764010374415

Boyle, S. (2014). Psychology Students Attitudes towards Mental Illness In relation to Stress, Coping Styles, Optimism and Mental Sarah Boyle Bachelor of Arts Psychology Degree DBS School of Arts, Dublin . Supervisor : Patricia Orr Head of Department : Dr. Sinead Eccles. March, 1-51.

Centers for Disease Control and Prevention. (2012). Attitudes toward mental illness: Results from the behavioral risk factor surveillance system. https://www.cdc.gov/hrqol/Mental_Health_Reports/pdf/BRFSS_Full Report.pdf

Corrigan, P. (2004). How stigma interferes with mental health care. American Psychologist, 59(7), 614625. https://doi.org/10.1037/0003-066X.59.7.614

Corrigan, P. W., Markowitz, F. E., \& Watson, A. C. (2004). Structural levels of mental illness stigma and discrimination. Schizophrenia Bulletin, 30(3), 481-491. https://doi.org/10.1093/oxfordjournals.schbul.a007096

Corrigan, P. W., \& Watson, A. C. (2002). Understanding the impact of stigma on people with mental illness. World Psychiatry, 1(1), 16-20.

Ewalds-Kvist, B., Högberg, T., \& Lützén, K. (2013). Impact of gender and age on attitudes towards mental illness in Sweden. Nordic Journal of Psychiatry, 67(5), 360-368. https://doi.org/10.3109/08039488.2012.748827

Gaebel, W., Rössler, W., \& Sartorius, N. (2016). The stigma of mental illness-end of the story? The Stigma of Mental Illness - End of the Story?, 1-656. https://doi.org/10.1007/978-3-319-27839-1 
Holzinger, A., Floris, F., Schomerus, G., Carta, M. G., \& Angermeyer, M. C. (2012). Gender differences in public beliefs and attitudes about mental disorder in western countries: A systematic review of population studies. Epidemiology and Psychiatric Sciences, 21(1), 73-85. https://doi.org/10.1017/S2045796011000552

Jang, H., Lim, J. T., Oh, J., Lee, S. Y., Kim, Y. I., \& Lee, J. S. (2012). Factors affecting public prejudice and social distance on mental illness: Analysis of contextual effect by multi-level analysis. Journal of Preventive Medicine and Public Health, 45(2), 90-97. https://doi.org/10.3961/jpmph.2012.45.2.90

Kemenkes RI. (2019). Hasil Riset Kesehatan Dasar Tahun 2018. Kementrian Kesehatan RI, 53(9), 16891699.

NATALIA, M., Suryani, S., \& Rafiyah, I. (2019). Health Professionals' Attitudes Towards Mental Illness Patients. Journal of Nursing Care, 2(1). https://doi.org/10.24198/jnc.v2i1.18488

Pascucci, M., La Montagna, M., Di Sabatino, D., Stella, E., Nicastro, R., Grandinetti, P., Testa, R., Parente, P., Janiri, L., Pozzi, G., Piemontese, G., Ventriglio, A., \& Bellomo, A. (2017). Stigma and attitudes towards mental illness: Gender differences in a sample of Italian medical students. European Psychiatry, 41(S1), S739-S739. https://doi.org/10.1016/j.eurpsy.2017.01.1359

Puspitasari, I. M., Garnisa, I. T., Sinuraya, R. K., \& Witriani, W. (2020). Perceptions, knowledge, and attitude toward mental health disorders and their treatment among students in an Indonesian University. Psychology Research and Behavior Management, 13, 845-854. https://doi.org/10.2147/PRBM.S274337

Reimer, B. (2019). A Comparison of the Relationship Between Gender Adherence, Sex, and Attitudes Toward Individuals With a Mental Illness.

Salve, H., Goswami, K., Sagar, R., Nongkynrih, B., \& Sreenivas, V. (2013). Perception and attitude towards mental illness in an urban community in South Delhi - A community based study. Indian Journal of Psychological Medicine, 35(2), 154-158. https://doi.org/10.4103/0253-7176.116244

Smith, V., Reddy, J., Foster, K., Asbury, E. T., \& Brooks, J. (2011). Public perceptions, knowledge and stigma towards people with schizophrenia. Journal of Public Mental Health, 10(1), 45-56. https://doi.org/10.1108/17465721111134547

Weiss, M. G., Ramakrishna, J., \& Somma, D. (2006). Health-related stigma: Rethinking concepts and interventions. Psychology, Health and Medicine, 11(3), 277-287. https://doi.org/10.1080/13548500600595053

Yuan, Q., Picco, L., Chang, S., Abdin, E., Chua, B. Y., Ong, S., Yow, K. L., Chong, S. A., \& Subramaniam, M. (2017). Attitudes to mental illness among mental health professionals in Singapore and comparisons with the general population. PLoS ONE, 12(11), 1-14. https://doi.org/10.1371/journal.pone.0187593 